\title{
Predicting rut depth induced by an 8-wheeled forwarder in fine-grained boreal forest soils
}

\author{
Jori Uusitalo ${ }^{1} \cdot$ Jari Ala-llomäki ${ }^{2} \cdot$ Harri Lindeman ${ }^{1} \cdot$ Jenny Toivio $^{3} \cdot$ Matti Siren $^{2}$
}

Received: 4 June 2019 / Accepted: 26 March 2020 / Published online: 20 April 2020

(C) The Author(s) 2020

\begin{abstract}
- Key message Rut depth in fine-grained boreal soils induced by an 8-wheeled forwarder is best predicted with soil moisture content, cumulative mass of machine passes, bulk density and thickness of the humus layer.

- Context Forest machines are today very heavy and will cause serious damage to soil and prevent future growth if forest operations are carried out at the wrong time of the year. Forest operations performed during the wettest season should therefore be directed at coarse-grained soils that are not as prone to soil damage.

- Aims The study aimed at investigating the significance of the most important soil characteristics on rutting and developing models that can be utilized in predicting rutting prior to forest operations.

- Methods A set of wheeling tests on two fine-grained mineral soil stands in Southern Finland were performed. The wheeling experiments were conducted in three different periods of autumn in order to get the largest possible variation in moisture content. The test drives were carried out with an 8-wheeled forwarder.

- Results Soil moisture content is the most important factor affecting rut depth. Rut depth of an 8-wheeled forwarder in finegrained boreal soil is best predicted with soil moisture content, cumulative mass of machine passes, bulk density and thickness of the humus layer.

- Conclusion The results emphasize the importance of moisture content on the risk of rutting in fine-grained mineral soils, especially with high moisture content values when soil saturation reaches $80 \%$. The results indicate that it is of high importance that soil type and soil wetness can be predicted prior to forest operations.
\end{abstract}

Keywords Bearing capacity $\cdot$ Trafficability $\cdot$ Compaction

\section{Introduction}

Forest machines are today rather heavy, typically from 20 to $40 \mathrm{t}$, and may cause significant soil deformation if forest

Handling Editor: Céline Meredieu

Contribution of the co-authors All authors participated in planning and collection of the material. Data analyses and writing of the paper was chiefly conducted by the first author (Jori UUSITALO). All authors participated in finalizing the paper.

Jori Uusitalo

jori.uusitalo@luke.fi

Jari Ala-Ilomäki

jari.ala-ilomaki@luke.fi

Harri Lindeman

harri.lindeman@luke.fi

Jenny Toivio

toiviojenny@gmail.com operations are not well planned. When the loading induced by the vehicle exceeds the bearing capacity of the soil, the soil begins to compact and deform. Exceeding the bearing capacity of soil leads to rutting and deformation, where soil particles
Matti Siren

matti.siren@luke.fi

1 Natural Resources Institute Finland (Luke), Production Systems, Korkeakoulunkatu 7, 33720 Tampere, Finland

2 Natural Resources Institute Finland (Luke), Production Systems, Maarintie 6, 02150 Espoo, Finland

3 Department of Forest Sciences, University of Helsinki, P.O. Box 27, FI-00014 Helsinki, Finland 
are displaced in both vertical and horizontal directions. Usually, soil deformation occurring during timber harvesting includes both elements of compaction and rutting. The bottom of ruts is the most probably compacted and displacement of soil particles in the lateral direction creates bulges at the edges of the ruts (Haas et al. 2016; Toivio et al. 2017; Marra et al. 2018).

Both rutting and compaction are harmful to future forest growth. Soil compaction implies limitations in oxygen and water supply to soil microorganisms and plants, and with negative consequences for soil respiration, microbiological activity and forest growth. Soil compaction is expressed typically directly with the increase of bulk density (BD), the decrease of soil porosity or indirectly with the increase of penetration resistance (PR). Rutting, instead, provides sinks for small puddles that may completely prevent the activity of roots and aerobic microorganism. Water has difficulties to percolate into the soil if the bottom of the rut is compacted. In addition to this biological harm, rutting may to a great extent be considered as one of the most important aesthetic problems caused by forest operations.

The magnitude of soil deformation predominantly designates how serious are the problems it causes. Kozlowski (1999) stated that the upper limits of BD at which roots do not penetrate wet soils vary from about 1.4 to $1.6 \mathrm{~g} \mathrm{~cm}^{-3}$ for fine-textured soils to $1.75 \mathrm{~g} \mathrm{~cm}^{-3}$ for coarser-textured soils. Rut depths of $10 \mathrm{~cm}$ are generally considered as the breakeven point for the acceptable level of ruts (Suomen Metsäkeskus 2019). In most soft wet soils, forest machines may cause almost $40 \mathrm{~cm}$ deep ruts (Uusitalo and Ala-Ilomäki 2013; Allman et al. 2017; Toivio et al. 2017). Ruts are chiefly categorized by rut depth, but the magnitude of rut damage may also be expressed by rut width (Edlund et al. 2012; Uusitalo et al. 2015), or a combination of rut depth and width (Liu et al. 2010). Haas et al. (2016) and Marra et al. (2018) have presented a methodology where volume of bulges and ruts can be measured with photogrammetry.

There are plenty of factors that affect the magnitude of rutting. These may be divided into three categories: soil properties, operational factors and technical factors. In mineral soils, moisture content may be regarded as the most important factor affecting soil bearing capacity (Han et al. 2006; VegaNieva et al. 2009) since increase in wetness weakens the physical bonds between the soil particles. Soil strength is also known to be affected by the average particle size (Freitag 1987; Smith et al. 1997). Obviously, moisture content and grain size distribution are strongly correlated; coarse-grained soils cannot hold high moisture contents (Karafiath and Nowatski 1978). The organic matter content in the soil has also been shown to affect the strength of the soil (Smith et al. 1997). Mineral soils in boreal forests usually contain an organic topsoil layer, the strength of which is distinctly below that of mineral soil.
Operational factors may also have a crucial role in soil deformation. Successful timing of the operation is the key element in avoiding significant soil disturbance; moisture sensitive soils should be harvested during dry or frozen periods. At harvest, logging trail networks should be carefully planned by directing main routes to the areas withstanding the heaviest load, minimizing the number of passes on trails with low bearing capacity or by widening trail width by steering the tires not to follow exactly the same track in every pass (Uusitalo et al. 2015). Rutting can also be minimized by processing the trees above the trail leading to formulation of protective brash mat (Murphy et al. 2009; Poltorak et al. 2018; Labelle et al. 2019). Technical factors that decrease soil damage include total mass of a machine (Ampoorter et al. 2010; Liu et al. 2010), tire dimensions (Haas et al. 2016), tire pressures (Eliasson 2005), tracks (Bygdén et al. 2003; Sakai et al. 2008; Haas et al. 2016), steering and transmission system (Edlund et al. 2012), distribution of vertical stress induced by tires or tracks (Vossbrink and Horn 2004; Horn et al. 2007) and traffic intensity (Ampoorter et al. 2010).

Although the phenomenon of rutting has been largely studied, fairly few studies have reported practical models predicting the magnitude of rutting (i.e. rut depths) in a forest environment. Modelling of ruts may in principal be constructed by two different methods. Firstly, we can construct simple machine-dependent empirical models for predicting rutting caused by a typical forest machine which means that the model is valid only for machines having similar tire size, tire pressure and load carried out. Sirén et al. (2013) investigated rut formation in Norway spruce dominated forests and noticed that in rather dry mineral soils rut depths were affected by cumulative mass hauled over the measurement point, thickness of the logging residue mat and soil stoniness. In fine grained mineral soils, rut depths can be predicted with cumulative mass, volumetric water content (VWC) and PR (Sirén et al. 2019b). Uusitalo and Ala-Ilomäki (2013) reported that ruts in pine bogs may best be predicted by a model including the volume of trees, shear modulus, machine type and number of passes as the main predictors. Allman et al. (2017) have shown that rut depth on mineral forest soils can be predicted by moisture content.

Secondly, machine-independent models can be constructed. Rut prediction can be estimated with two empirical model structures; with soil properties - soil strength (PR) relationship and with empirical formulas describing the interaction between soil and wheel, such as the WES methodology. The methodology is based on empirically created, nondimensional wheel numerics which relate the measured PR to the load carried out by the tire and various principal tire dimensions (Turnage 1984). Vega-Nieva et al. (2009) applied the WES method with the formulas and empirical parameters suggested in the ECOWOOD project (Saarilahti 2002) and found out that the models produce reliable results. 
Many previous investigations have stressed the importance of moisture as the main factor of soil strength, especially in fine-grained soils (Ayers and Perumpral 1982; Elbanna and Witney 1987; Smith et al. 1997; Uusitalo et al. 2019). Moisture content of soil varies significantly by season and weather conditions which mean that soil strength is also highly variable. As much as $80-90 \%$ of the commercial logging operations in the Nordic countries are carried out with very similar forest machines having eight $700 \mathrm{~mm}$ wide tires, it is therefore practical to investigate the direct relation between soil properties, traffic intensity and rutting caused by these vehicles.

The study aimed at exploring the most important characteristics in predicting rutting and to developing suitable models for predicting rutting on fine-grained mineral soils caused by the most typical forest machine used in these conditions. The model to be developed should be simple and adequate for practical use in forestry. We had a hypothesis that in fine-grained soils, soil moisture content has a very important role. Therefore, we decided to arrange wheeling experiments on the same fine-grained forest area in three different periods of the year.

\section{Materials and methods}

Field studies were conducted on a test site that comprised two separate test blocks, A and B, located in the municipality of Vihti in Southern Finland. Block A $\left(60^{\circ} 24.6\right.$ N, 24 23.2 E, around $60 \mathrm{~m}$ above sea level) was an even-aged Norway spruce (Picea abies (L.) Karst) stand on a silty-clayey soil with a shallow $(1-5 \mathrm{~cm})$ humus horizon. The relief was an even slope with a minor inclination to the northwest. The soil was prepared by ploughing before planting approx. 30 years ago. Block B $\left(60^{\circ} 24.4 \mathrm{~N}, 24^{\circ} 22.4 \mathrm{E}\right.$, around $70 \mathrm{~m}$ above sea level) was a forest of natural origin with different tree species and age classes. The stand was mostly Norway spruce dominated with a mixture of birch (Betula pendula Roth) and aspen (Populus tremula L.). It was located in a dell and characterised by a silty-sandy soil with a variable thickness $(5-20 \mathrm{~cm})$ of organic layer with a shallow peat layer in moist patches.

Block A consisted of three columns (numbers 1-3), while block B had two columns (4-5). Each column contained three parallel sub-columns that comprised 4 consecutive study plots, $5 \mathrm{~m}$ in length and $5 \mathrm{~m}$ in width. Each study plot was named with a 3-digit code, the first digit indicating the driving line (sub-column), the second the column, the third indicating the study plot (e.g. $321=$ driving line (sub-column) 3, column 2, study plot 1) (Fig. 1). In all, the study material comprised 52 sample plots; Block A $36(12 \times 3)$ and B $16(8 \times 2)$ sample plots. Within each sample plot, six measurement points were marked on the ground. The measurement points were placed along the planned trails of the machine; $0.5,2.5$ and $4.5 \mathrm{~m}$ from the starting point of the plot.

Prior to test trials, diameter at breast height (dbh) of all trees within the sample plot was measured. The height of three randomly selected sample trees was measured with the Suunto clinometer. Stand characteristics for each sample plot were calculated using the KPL software developed at the Finnish Forest Research Institute (Heinonen 1994). Stand characteristics include stand density $(N)$, average diameter at breast height, average height $(H)$, basal area of trees (BA) and volume of trees $(V)$. Means of the main stand characteristics are presented in Table 1 . The study sites were harvested prior to the first test period in August with a 6-wheeled John Deere 1270E harvester with a boom reach of $10 \mathrm{~m}$. The harvester travelled strictly outside the actual study trails to keep the test site intact. Trees were processed outside the study trails. Consequently, the study trails had no ruts, no compaction nor branches protecting the soil prior to trials with the forwarder. In block A, trees were planted in rows, the distance between rows being roughly $2.5 \mathrm{~m}$. Trails were placed to enable forwarder tyres to run between the stumps of the cut trees. Block B was of natural origin which meant the forwarder tyres travelled over a number of stumps in the test drives. While harvesting, boundaries of the study plots were marked on the ground.

Test drives were conducted during three periods in the autumn of 2015, the first test in early September (driving line 2), the second in November (driving line 3) and the third in December (driving line 1). The maximum amount of machinery passes was 10, which was always reached except on block $\mathrm{B}$ in November as the bearing capacity collapsed due to high soil moisture content after the third pass. As a consequence, on block B, the tests were performed in September and November only. The test drives were carried out with an 8wheeled Ponsse Elk forwarder equipped with Nokia Forest King F2 710/45-26.5 tires, universal Olofsfors EVO tracks on the rear bogie and Superhokki 160 TS chains on the rear wheels of the front bogie. Forwarder operator was instructed to pass the same wheel tracks for each consecutive pass. Forwarder tire pressure was approximately $400 \mathrm{kPa}$. The mass of the forwarder with the tracks and chains was $20,000 \mathrm{~kg}$. In each test drive, the forwarder was loaded with $9800 \mathrm{~kg}$ of pulpwood resulting in a total mass of $29,800 \mathrm{~kg}$.

Prior to the driving test, the penetration resistance (PR) of all six measurement points within each plot was measured with an Eijelkamp Penetrologger 0615SA penetrometer consisting of a $11.28 \mathrm{~mm}$ diameter $\left(1 \mathrm{~cm}^{2}\right), 60$-degree cone. The penetrometer has a load cell and an ultrasonic depth sensor, and it captures readings at $1 \mathrm{~cm}$ depth increments. The mean of the readings $0 \ldots$ $20 \mathrm{~cm}$ below the surface of the soil, named here PR020, was used as the final PR value to describe strength of soil.

Two soil samples were taken from the centremost sample points of each study plot with a core sampler, $500 \mathrm{~mm}$ in height and $25 \mathrm{~mm}$ in diameter. In December, a round sampling tube 


\section{Block A}

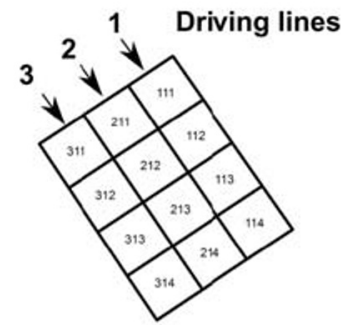

Column 1

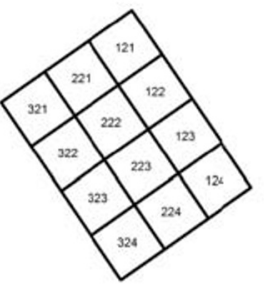

Column 2

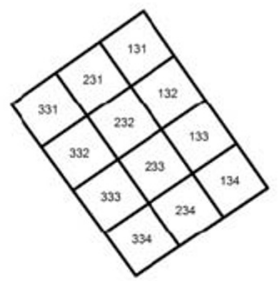

Column 3

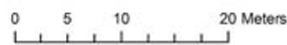

Column

Subcolumn

Sample plot

-Rut

- Measurement point

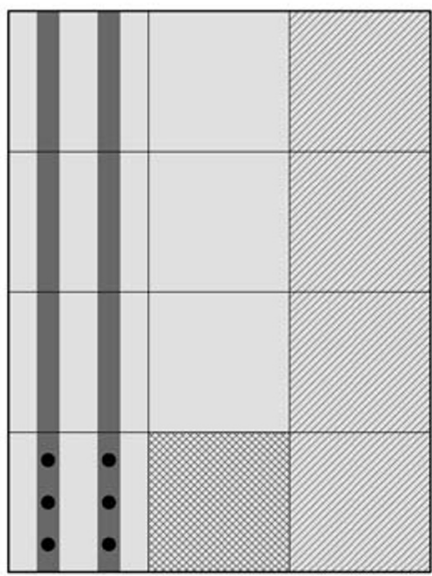

Block B

Column 4
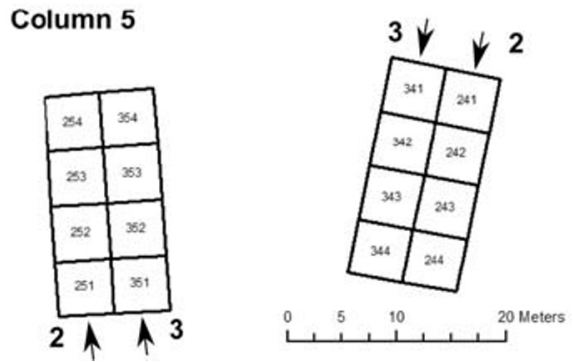

Fig. 1 Layout of the block-column-sub-column sample plot design on the Vihti site

with a diameter of $46 \mathrm{~mm}$ was used. The soil core extracted from the soil was divided into three sections, an organic layer and two mineral soil subsamples $10 \mathrm{~cm}$ in length, the first starting from the upper boundary of the mineral soil. The thickness of the organic layer was measured in the field while the bulk density (BD), volumetric water content (VWC), soil organic matter (SOM) and grain size distribution were later analysed in the laboratory, separately for the upper $(0-10 \mathrm{~cm})$ and lower $(10$ $20 \mathrm{~cm}$ ) section of the inorganic part of the core sample.

Table 1 Mean of the main stand characteristic by columns for the two studied stands (block A and B)

\begin{tabular}{llll}
\hline Column & BA $\left(\mathrm{m}^{2} / \mathrm{ha}\right)$ & DBH $(\mathrm{cm})$ & Stand volume $\left(\mathrm{m}^{3} / \mathrm{ha}\right)$ \\
\hline 1 & 37 & 14.6 & 307 \\
2 & 32 & 13.6 & 256 \\
3 & 28 & 13.5 & 222 \\
Block A mean & 32 & 13.9 & 262 \\
4 & 32 & 20.8 & 341 \\
5 & 26 & 20.4 & 257 \\
Block B mean & 29 & 20.6 & 299 \\
\hline
\end{tabular}

$B A$ basal area, $D B H$ diameter at breast height $(1.3 \mathrm{~m})$
The mineral soil samples were analysed in the laboratory with standard laboratory procedures for bulk density, water content and grain size distribution. Since the initial analyses showed that the upper soil samples are clearly more significant from a bearing capacity point of view than the lower samples, the final analyses focused only on the upper soil samples. Hence, the variables BD, VWC, SOM and contents of each grain size class refer to values derived from the upper soil sample $(0-10 \mathrm{~cm}$ from the top of the mineral soil). Characteristics of the test soils in terms of grain size distribution and SOM are shown in Table 2.

After each test run, the depth of the ruts caused by the forwarder at each measurement point was measured with a horizontal laser levelling device and a laser levelling rod equipped with a laser beam detector. The device was first placed at a random location along the trail to obtain a reference height, which was then marked on the surface of a nearby tree. Sample lines across the trails were marked to the ground in order to keep measuring point locations constant. The ground level reference level outside the wheel ruts was first measured on the left and the right of the wheel rut centre. The laser levelling rod used for measuring the height was pushed lightly against the ground to compact any loose surface layer 
Table 2 Means of proportion of grain sizes of the inorganic component of soil samples (the first $10 \mathrm{~cm}$ from the starting point of the mineral soil) by columns. $N=52$

\begin{tabular}{|c|c|c|c|c|c|c|c|}
\hline Columns & $\begin{array}{l}\text { Clay } \\
(<0.002 \mathrm{~mm})\end{array}$ & FSi/MSi (0.002-0.02 mm) & $\mathrm{CSi}(0.02-0.063 \mathrm{~mm})$ & $\mathrm{FSa}(0.063-0.2 \mathrm{~mm})$ & $\mathrm{MSa}(0.2-0.63 \mathrm{~mm})$ & $\mathrm{CSa}(0.63-2 \mathrm{~mm})$ & SOM \\
\hline 1 & 50.7 & 30.3 & 8.1 & 6.7 & 3.6 & 0.7 & 9.7 \\
\hline 2 & 51.6 & 26.6 & 5.9 & 8.3 & 6.3 & 1.4 & 9.4 \\
\hline 3 & 44.7 & 30.6 & 5.3 & 6.5 & 9.2 & 3.7 & 8.5 \\
\hline 4 & 25.6 & 7.6 & 4.6 & 32.8 & 20.3 & 9.1 & 8.2 \\
\hline 5 & 35.8 & 8.9 & 2.9 & 20.9 & 21.6 & 9.9 & 7.6 \\
\hline
\end{tabular}

FSi fine silt, MSi medium silt, CSi coarse silt, $F S a$ fine sand, MSa medium sand, CSa coarse sand, SOM soil organic matter (\% of the total mass of dry soil)

vegetation, and the distance to the reference mark was calculated by reading the level of the laser beam detector attached to the surface of the laser levelling rod. The depth of both wheel ruts was measured by placing the laser levelling rod at the bottom of the rut, reading the relative height of the bottom and calculating the depth of the ruts by comparing these values to the closest ground reference level. The total over-driven mass for each pass (mass) was calculated by summing up the mass of the loaded forwarder $(29,800 \mathrm{~kg})$ for each time it passes the sample plot.

Modelling the relationship between rut depths and the most important predictors was executed using the IBM SPSS v. 25 software following the MIXED procedure and applying the restricted maximum likelihood (REML) estimation method. For repeated measurements of rut depths, let $k$ denotes the number of the machine pass and $j$ denotes sample plot within column $i$. The basic form of the mixed model predicting PR characteristics was as follows:

$R u t_{i j k}=b_{0}+b X+u_{i}+v_{i j}+y_{i j k}$

where $R u t_{i j k}$ is the dependent variable for Rut, $b_{0}$ is the constant, $b$ (row) is the vector of the (fixed) regression coefficients, $X$ (column) is the vector of the continuous and binary explanatory variables, $u_{i}$ is the random term (variance) for block $i, v_{i j}$ is the random term (variance) for sample plot $j$ in block $i$, and $y_{i j k}$ is the auto-regressive error term for repeated measurements $i j k$.

In order to account for correlation for repeated measurements of the same measurement point, residual effect was modelled with first order auto-regressive AR (1) covariance structure meaning that successive measurements are more correlated, with correlation coefficient $\rho_{\text {meas }}$ and variance $\sigma_{\text {meas }}^{2}$. The fit of the models was compared by using the Akaike Information Criterion (AIC). It was noticed that the relationships between the dependent and the most important predictors are not linear. Initial examination of the data showed clearly that rut depth increased exponentially with high VWC values, especially when VWC reached $45 \%$ where soil may be regarded as almost fully saturated. Therefore, suitable transformations to the predictors were made prior to analyses.

\section{Results}

Means of the main soil properties by subcolumns are presented in Table 3. As expected, VWC increased from September (driving line 2) to November (driving line 3) markedly, but only slightly from November to December (driving line 1) (Table 3). The thickness of humus layer varied $2.5-11.5 \mathrm{~cm}$ and PR020 $0.841-2.134 \mathrm{kPa}$. The correlation matrix of the most important soil characteristics is presented in Table 4. Clay content, BD, SOM and VWC are significantly correlated with each other. Penetration resistance is only correlated with VWC.

The thickness of the humus layer and VWC has the greatest influence on the rut depths. The role of VWC seems to be crucial, especially with high VWC values. Rut depths of the first three machine passes by the number of pass and VWC are shown in Fig. 2. Mean of rut depths stays below $10 \mathrm{~cm}$ with low VWC values. The relationship between VWC and rut depth is rather linear until a VVW of roughly $45 \%$, i.e. the soil, is almost or completely saturated. After that the risk of the bearing capacity of soil collapsing increases exponentially. The high variation of rut depths with high VWC values can partly be explained by the role stumps and roots of trees that increase variation of dynamic loads induced by wheels.

The best models for predicting rut depth based on moisture content as the main predictor are presented in Table 5. Raising VWC to the third power yielded the best results in explaining rut depth. In addition, the cumulative mass of machine passes, BD and the thickness of the humus layer were also found to be significant predictors in the model, which already contained $\mathrm{VWC}^{3}$ as the main predictor (model 1). Tree stock included a rather small variation (Table 1). It is therefore no wonder that tree characteristics were not found to be significant in modelling rut depths.

The behaviour of model 1 is illustrated in Fig. $3 \mathrm{a}$ and $\mathrm{b}$ with two different soil types. The first soil (Fig. 3a) represents fine-grained soil with high $\mathrm{BD}\left(1.3 \mathrm{~g} \mathrm{~cm}^{-3}\right)$ and thin humus layer $(4 \mathrm{~cm})$ and the other one (Fig. 3b) fine-grained soil with low BD $\left(0.7 \mathrm{~g} \mathrm{~cm}^{-3}\right)$ and thick humus layer $(12 \mathrm{~cm})$. Rut depth was also modelled with a structure where PR was set as the main predictor (model 3). Including the thickness of the 
Table 3 Means of volumetric water content (VWC), bulk density (BD), mean penetration resistance $0-20 \mathrm{~cm}$ below the surface of the soil (PR020) and thickness of humus layer (humus layer) by sub-columns. Each subcolumn includes 4 samples

\begin{tabular}{llllll}
\hline Driving line & Sub-column & VWC $(\%)$ & BD $\left(\mathrm{g} / \mathrm{cm}^{3}\right)$ & PR020 $(\mathrm{kPa})$ & Humus layer $(\mathrm{cm})$ \\
\hline 1 & 11 & 40.9 & 1.05 & 0.920 & 2.5 \\
12 & 40.4 & 1.10 & 0.951 & 3.6 \\
2 & 40.2 & 1.05 & 1.050 & 4.2 \\
& 13 & 40.5 & 1.07 & 0.974 & 3.4 \\
& Mean & 25.5 & 0.82 & 1.585 & 3.5 \\
& 21 & 21.5 & 0.75 & 1.562 & 2.8 \\
& 22 & 24.9 & 0.92 & 2.137 & 4.4 \\
& 23 & 36.3 & 1.11 & 1.251 & 5.1 \\
& 24 & 37.9 & 1.26 & 1.132 & 10.4 \\
& 25 & 29.2 & 0.97 & 1.533 & 5.2 \\
& Mean & 36.4 & 0.88 & 0.987 & 2.6 \\
& 31 & 33.1 & 0.80 & 0.841 & 2.1 \\
& 32 & 39.2 & 1.00 & 1.209 & 8.9 \\
& 33 & 48.5 & 1.21 & 0.861 & 4.3 \\
Mean & 34 & 1.23 & 1.055 & 4.5 \\
& 35 & 37.8 & 0.96 & 1.002 &
\end{tabular}

humus layer in the model slightly improved the fit of the model (model 4). Including both PR and VVW as predictors in the same model is not wise since they are so strongly correlated.

\section{Discussion}

Wheeling tests were executed in identical soil at three different points of time during the autumn in order to find out the effect of soil moisture on rutting. As expected, soil moisture content may be regarded as the most important factor in predicting

Table 4 Pearson correlation coefficients and their significances $(P$ value) between the main soil characteristics. $N=52$. "Double asterisks" indicate that correlation is significant at the 0.01 level. Abbreviations are as follows:

\begin{tabular}{|c|c|c|c|c|c|}
\hline & PR020 & $\mathrm{BD}$ & VWC & Clay & $\mathrm{SOM}$ \\
\hline \multirow[t]{2}{*}{ PR020 } & 1 & -0.268 & $-0.536^{* *}$ & 0.013 & 0.010 \\
\hline & & 0.054 & 0.000 & 0.924 & 0.945 \\
\hline \multirow[t]{2}{*}{$\mathrm{BD}$} & & 1 & $0.700^{* *}$ & $-0.616^{* *}$ & $-0.673^{* * *}$ \\
\hline & & & 0.000 & 0.000 & 0.000 \\
\hline \multirow[t]{2}{*}{ VWC } & & & 1 & $-0.397^{* *}$ & $-0.457^{* * *}$ \\
\hline & & & & 0.004 & 0.001 \\
\hline \multirow[t]{2}{*}{ Clay } & & & & 1 & $0.631^{\text {*** }}$ \\
\hline & & & & & 0.000 \\
\hline SOM & & & & & 1 \\
\hline
\end{tabular}

PR020 mean penetration resistance $0-20 \mathrm{~cm}$ below the surface of the soil, $V W C$ volumetric water content, $B D$ bulk density $\left(\mathrm{g} / \mathrm{cm}^{3}\right)$, Clay proportion of clay $(<0.002 \mathrm{~mm})$ in the inorganic matter $(\%)$, SOM soil organic matter (\% of the total mass of soil) rutting of forest machines in fine-grained mineral soils. The findings are in line with the previous findings that have focused either on moisture content-soil strength relationship (Ayers and Perumpral 1982; Elbanna and Witney 1987; Smith et al. 1997; Uusitalo et al. 2019) or moisture content-soil disturbance relationship (Cambi et al. 2016; Allman et al. 2017; Sirén et al. 2019a, b).

In distinction to previous findings, we stress the radical changes of bearing capacity with high moisture content values. It seems that moisture content bearing capacity relationship is almost linear from dry to almost saturated soil and after that the bearing capacity of the soil collapses in many cases. In our data, the radical changes in the bearing capacity occurred at VWC values of roughly $45 \%$. This corresponds to saturation of roughly $80 \%$. This phenomenon can be explained by significant changed in the cohesive forces between the soil particles when complete or almost complete saturation has been achieved. We modelled the relationship between rut depth and moisture content by raising VWC to third power.

In addition to soil moisture content, the cumulative mass of the machine passes has a significant effect on the rut depth. In the final model, the cumulative mass of machine passes was transformed to a logarithmic scale. It corresponds to the effect of the number of passes on rut depths, where the effect of the first pass is the greatest and increase in rut depth after the consecutive passes diminishes to zero. This is a very wellknown phenomenon presented and modelled in numerous studies (e.g. Abebe et al. 1989).

BD and the thickness of the humus layer were also found to be significant predictors of rutting. The mean of $\mathrm{BD}$ in the sample plots varied between 0.75 to 
Fig. 2 Rut depths of the first three machine passes by VWC in the soil

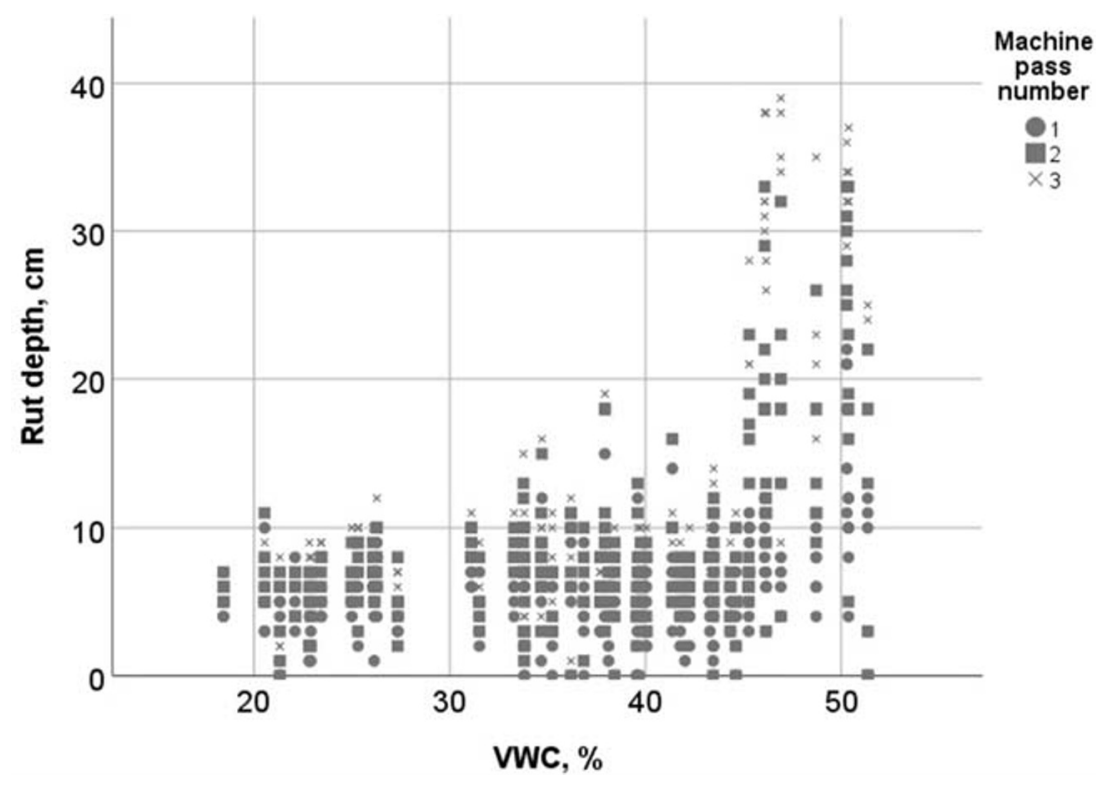

$1.26 \mathrm{~g} \mathrm{~cm}^{-3}$ which is consistent with previous findings in boreal soils (Périé and Ouimet 2011; Sirén et al. 2019b). It is not a surprise that $\mathrm{BD}$ of the mineral soil layer is correlated to bearing capacity, since the relationship between BD and soil strength (in terms of PR) has been reported by numerous researchers (Ayers and Perumpral 1982; Elbanna and Witney 1987; Smith et al. 1997; Uusitalo et al. 2019). The well-known negative correlation between BD and SOM (e.g. Heiskanen et al. 2018) was also found in our data set.
The thickness of the humus layer in the sample plots varied between 2.5 and $11.4 \mathrm{~cm}$, the mean being $4.5 \mathrm{~cm}$ which is in line with the findings of a large data set from Finland (Westman 1990). The strength of the organic layer is known to be rather weak. PR of the organic soil is known to vary between 300 and $600 \mathrm{kPa}$ (Uusitalo and Ala-Ilomäki 2013) which means that after two to three machine passes, the organic layer has been displaced horizontally or compacted against the mineral soil. It is therefore no surprise that the thickness of the humus layer was found to be a significant

Table 5 Mixed linear models predicting rut depth $(\mathrm{cm})$. The parameters are as follows:

\begin{tabular}{|c|c|c|c|c|c|c|c|c|}
\hline \multirow[t]{2}{*}{ Model parameter } & \multicolumn{2}{|l|}{1} & \multicolumn{2}{|l|}{2} & \multicolumn{2}{|l|}{3} & \multicolumn{2}{|l|}{4} \\
\hline & Estimate (SE) & Sig. & Estimate (SE) & Sig. & Estimate (SE) & Sig. & Estimate (SE) & Sig. \\
\hline \multicolumn{9}{|l|}{ Fixed } \\
\hline Intercept & $-35.3(3.43)$ & .000 & $-39.9(2.30)$ & .000 & $-32.4(2.59)$ & .000 & $-37.3(2.41)$ & .000 \\
\hline Ln Mass, kg & $3.86(0.183)$ & .000 & $3.86(0.183)$ & .000 & $3.86(0.183)$ & .000 & $3.86(0.183)$ & .000 \\
\hline $\mathrm{VWC}^{3}, \%$ & $0.0000917(0.0000166)$ & .001 & $0.0000431(0.0000145)$ & .005 & & & & \\
\hline PR020 & & & & & $-1.02(0.536)$ & .059 & $-0.978(0.525)$ & .064 \\
\hline $\mathrm{BD}, \mathrm{g} / \mathrm{cm}^{3}$ & $-5.76(3.16)$ & .075 & & .000 & & & & \\
\hline Humus layer, $\mathrm{cm}$ & $1.11(0.172)$ & .000 & $0.681(0.169)$ & .001 & & & $0.883(0.166)$ & .000 \\
\hline \multicolumn{9}{|l|}{ Random } \\
\hline$u_{\mathrm{i}}$ & 0.909 & .535 & 0.795 & .538 & 10.1 & .211 & 1.24 & .472 \\
\hline$v_{\mathrm{ij}}$ & 6.54 & .000 & 6.99 & .000 & 10.2 & .000 & 7.84 & .000 \\
\hline$\sigma_{\text {meas }}^{2}$ & 16.3 & .000 & 16.3 & .000 & 16.3 & .000 & 16.3 & .000 \\
\hline$\rho_{\text {meas }}$ & 0.707 & .000 & 0.707 & .000 & 0.707 & .000 & 0.707 & .000 \\
\hline AIC & 6220.7 & & 6228.1 & & 6227.7 & & 6211.8 & \\
\hline
\end{tabular}

Ln Mass natural logarithmic of the cumulative mass of machine passes, $V W C^{3}$ volumetric water content raised to the third power, $P R 020$ mean penetration resistance $0-20 \mathrm{~cm}$ below the surface of the soil, BD bulk density of the soil, Humus layer thickness of the humus layer, AIC Akaike Information Criterion 

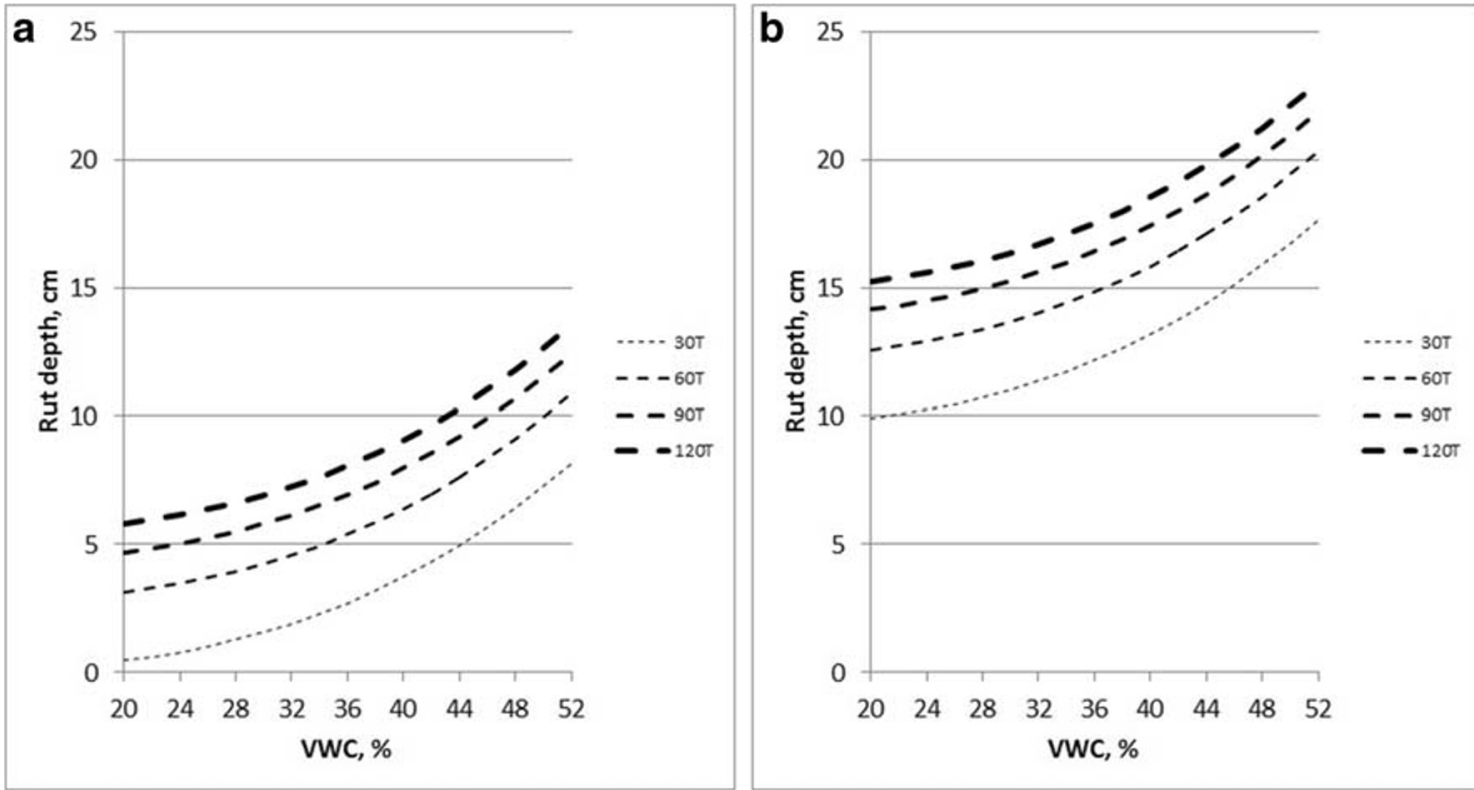

Fig. 3 Influence of the VWC and cumulative mass of machine passes on rut depth with a constant BD of $1.3 \mathrm{~g} \mathrm{~cm}^{-3}$ and thickness of humus layer of $4 \mathrm{~cm}$ (a) and with $0.7 \mathrm{~g} \mathrm{~cm}^{-3}$ and $12 \mathrm{~cm}$, respectively (b). 30T to $120 \mathrm{~T}$ refers to cumulative masses between $30 \mathrm{t}$ and $120 \mathrm{t}$

predictor of rut depth. Recently, it has been shown that the thickness of the humus layer is well correlated with the type of vegetation coverage and clay content (Heiskanen et al. 2018). It means that the thickness of the humus layer may, to a certain extent, be estimated with topographical and remote sensing data.

The thickness of the humus layer has a crucial role in formation of the rut depth, especially with regard to the first pass of the machine. In the second and consecutive passes, the characteristics of the inorganic layer play the major role. The greater amount of water the soil can hold the more plastic the soil gets. In our experiments, the deepest ruts formed in the plots that were situated in a dell characterized by a silty-sandy soil. The plots situated on a slope had a higher consistency of clay, but the soil did not reach saturation point even during the most humid season of the year. This can be explained by the low water permeability of fat clay soils (Karafiath and Nowatski 1978).

In addition to the model structure based on the moisture content, rut depth can also be estimated with the model structure where PR is set as the main predictor. Including both VWC and PR in the model, predicting rutting is not very wise since these variables are strongly correlated. PR as a predictor has its strengths and weaknesses. PR treats the soil types independently, not taking into account whether the soil is inorganic or organic. A low PR inevitably leads to deep ruts. The weak point of PR information is that the moisture content has a different bearing with strength in organic and inorganic soils. Therefore, if the moisture content of soil changes, one should know the thickness of the humus layer and PR for the humus layer and inorganic layer separately in order to adjust the PR results to the updated moisture content.
Variation of rut depth with low PR values was especially high. Our data included ten plots out of 52 where the PR of the first $20 \mathrm{~cm}$ in soil was less than $800 \mathrm{kPa}$, but heavy traffic did not always result in serious rut depths. The variation in thickness of the humus layer has distinct influence on that. The data also indicates that differences of PR in non-saturated and saturated soils are not as radical as the differences in rut depths. This is good to keep in mind when the classic WES methodology is applied in predicting rut depth. In this sense, moisture content may be regarded as a more powerful predictor of rut

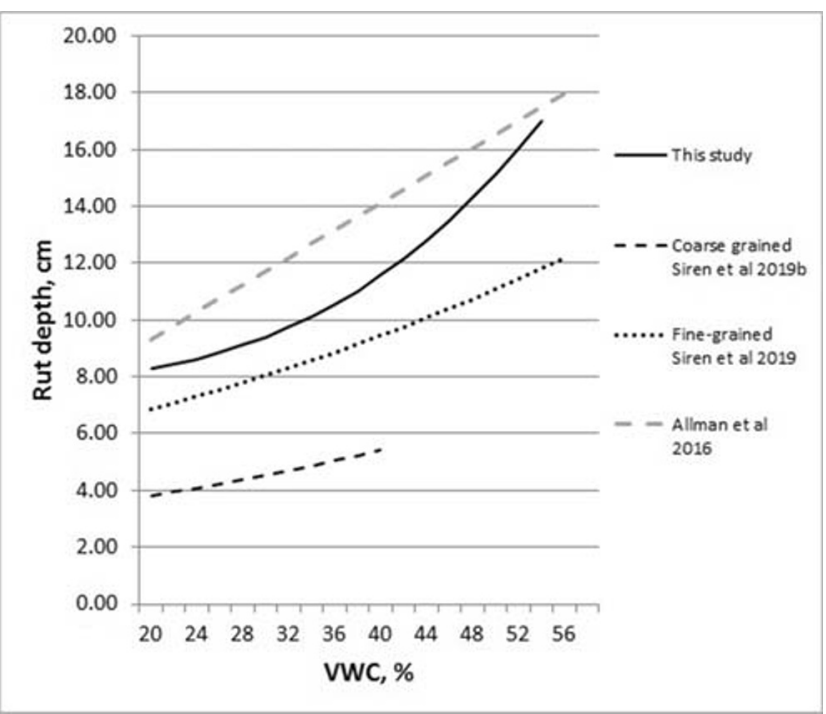

Fig. 4 Comparison of the models predicting rutting by forest machine in relation to VWC of the inorganic layer at a depth of $0-10 \mathrm{~cm}$ with the models presented in Table 6 
Table 6 Summary of the models predicting rut depth in fine-grained and mid-grained soils. The proportion of soil type refers to the number of sample plots falling into the specific category out of all sample plots (e.g. 5/6 means that five sample plots out of six samples fall into the specific category)

\begin{tabular}{lllll}
\hline Reference & \multicolumn{2}{l}{ Proportion of soil type from all sample plots } & Model \\
\cline { 2 - 4 } & Clay $>10 \%$ & Clay $<10 \%$, fines $>30 \%$ & Clay $<10 \%$, fines $<30 \%$ & \\
\hline Allman et al. (2017) & - & $5 / 6$ & $1 / 6$ & $\mathrm{RUT}=4.52+0.24 \times \mathrm{GVC}$ \\
Sirén et al. (2019a) & - & $1 / 7$ & $6 / 7$ & $\ln (\mathrm{RUT})=0.285+0.000011 \times$ mass $+0.016 \times \mathrm{VWC}$ \\
Sirén et al. (2019b) & $3 / 7$ & $1 / 7$ & $3 / 7$ & $\ln (\mathrm{RUT})=0.028+0.0000084 \times$ mass $+0.079 \times \mathrm{VWC}$ \\
This study, model 1 & $13 / 13$ & - & - & RUT $=-35.3+\ln ($ mass $)+0.0000917 \times$ VWC $-5.76 \times$ \\
& & & & BD $+1.11 \times$ humus layer \\
\hline
\end{tabular}

RUT rut depth, cm; GVC Gravimetric water content, \%. Other abbreviations as presented earlier

depth since it takes into account the extreme influence of degree of saturation on rutting more efficiently.

We believe that model 1 where VWC, cumulative mass of machine passes, $\mathrm{BD}$ and thickness of the humus layer are the main predictors is versatile enough to be utilized in various circumstances of forest soils where the inorganic layer is comprised of fine particles. The model performance in comparison to the models presented by Allman (2017), Sirén et al. (2019b) in finegrained and Sirén et al. (2019a) in middle grained soils is illustrated in Fig. 4, and the summary of the parameters used in these models is shown in Table 6. In the study by Allman et al. (2017), there was no control of machine passes nor cumulative mass, but only the final rut depths after all machine traffic were reported. The study by Sirén et al. (2019b) in fine-grained mineral soil included sample plots with a considerably smaller proportion of clay content. The difference between fine-grained and midgrained soils in terms of rut depth is significant.

The models created in this study may be applied in predicting the risk of rutting prior to forest operations. Apparently, moisture content in the soil will in the future be predicted with sophisticated hydrological models that are based on topographical and meteorological data and on data of growing stock. Significant steps are also being taken in the prediction of soil properties (Heiskanen et al. 2018). This kind of model structures will give forest practitioners possibilities to adjust the timing of forest operations, avoid sensitive area within the stand and fine-tune machine specifications.

The models presented should give reliable estimates on similar soils and when similar machine specifications are used. If total mass of machine or mass distribution between front and rear bogies significantly differs from the machine specifications used in this study, there is no guarantee that models give unbiased predictions. However, we believe that the same soil parameters will stay as the most important components in prediction of rut depth. Moreover, it has to be noticed that the wheeling experiments were performed without any protective brush mat. It is well-known that the protective mat effectively reduces magnitude of soil displacement (Poltorak et al. 2018; Labelle et al. 2019).

\section{Conclusions}

Rutting of soil on fine-grained forest soils caused by an 8wheeled forest machine can be predicted rather confidently. Soil moisture content and thickness of the humus layer are the most important soil characteristics in predicting rut depth. In addition to these, soil bulk density is significantly important predictor affecting rutting, but the parameter is rather laborious to measure or predict in practice. The seasonal variation in soil moisture is high in boreal forests, and wet conditions can interrupt mechanical operations on low trafficability sites. The results indicate that it is of high importance that soil type and soil wetness can be predicted prior to forest operations.

Acknowledgements Open access funding provided by Natural Resources Institute Finland (LUKE). We would like to express our gratitude to Metsä Forest and the personnel of Metsäkoneurakointi Pekka Liiri Oy for their support.

Funding information The work has been accomplished in the EFFORTE project that has received funding from the Bio Based Industries Joint Undertaking under the European Union's Horizon 2020 research and innovation programme under grant agreement No 720712.

Data availability The data may be accessed with special request from the corresponding author.

\section{Compliance with ethical standards}

Conflict of interest The authors declare that they have no conflict of interests.

Open Access This article is licensed under a Creative Commons Attribution 4.0 International License, which permits use, sharing, adaptation, distribution and reproduction in any medium or format, as long as you give appropriate credit to the original author(s) and the source, provide a link to the Creative Commons licence, and indicate if changes were made. The images or other third party material in this article are included in the article's Creative Commons licence, unless indicated otherwise in a credit line to the material. If material is not included in the article's Creative Commons licence and your intended use is not permitted by statutory regulation or exceeds the permitted use, you will need to obtain permission directly from the copyright holder. To view a copy of this licence, visit http://creativecommons.org/licenses/by/4.0/. 


\section{References}

Abebe AT, Tanaka T, Yamazaki M (1989) Soil compaction by multiple passes of a rigid wheel relevant for optimization of traffic. J Terramech 26:139-148. https://doi.org/10.1016/0022-4898(89) 90003-7

Allman M, Jankovský M, Messingerová V, Allmanová Z (2017) Soil moisture content as a predictor of soil disturbance caused by wheeled forest harvesting machines on soils of the Western Carpathians. J For Res 28:283-289. https://doi.org/10.1007/ s11676-016-0326-y

Ampoorter E, Van Nevel L, De Vos B et al (2010) Assessing the effects of initial soil characteristics, machine mass and traffic intensity on forest soil compaction. For Ecol Manag 260:1664-1676. https://doi. org/10.1016/j.foreco.2010.08.002

Ayers P, Perumpral J (1982) Moisture and density effect on cone index. Trans ASAE 25:1169-1172. https://doi.org/10.13031/2013.33691

Bygdén G, Eliasson L, Wästerlund I (2003) Rut depth, soil compaction and rolling resistance when using bogie tracks. J Terramech 40:179 190. https://doi.org/10.1016/j.jterra.2003.12.001

Cambi M, Certini G, Fabiano F et al (2016) Impact of wheeled and tracked tractors on soil physical properties in a mixed conifer stand. IForest:9. https://doi.org/10.3832/ifor1382-008

Edlund J, Bergsten U, Löfgren B (2012) Effects of two different forwarder steering and transmission drive systems on rut dimensions. J Terramech 49:291-297. https://doi.org/10.1016/j.jterra.2012.03.004

Elbanna EB, Witney BD (1987) Cone penetration resistance equation as a function of the clay ratio, soil moisture content and specific weight. J Terramech 24:41-56. https://doi.org/10.1016/0022-4898(87)90058-9

Eliasson L (2005) Effects of forwarder tyre pressure on rut formation and soil compaction. Silva Fenn Monogr 39:549-557. https://doi.org/10. $14214 /$ sf.366

Freitag DR (1987) A proposed strength classification test for fine-grained soils. J Terramech 24:25-39. https://doi.org/10.1016/0022-4898(87) 90057-7

Haas J, Hagge Ellhöft K, Schack-Kirchner H, Lang F (2016) Using photogrammetry to assess rutting caused by a forwarder-a comparison of different tires and bogie tracks. Soil Tillage Res 163:14-20. https://doi.org/10.1016/j.still.2016.04.008

Han H, Page-dumroese D, Han S (2006) Effects of slash, machine passes, and soil moisture on penetration resistance in a cut-to-length harvesting. Int J For Eng 17:11-24. https://doi.org/10.1080/14942119. 2006.10702532

Heinonen J (1994) Koealojen puu- ja puustotunnusten laskentaohjelma KPL. Käyttöohje. Finnish For Res Institute, Res Pap 504:80

Heiskanen J, Hallikainen V, Uusitalo J, Ilvesniemi H (2018) Co-variation relations of physical soil properties and site characteristics of Finnish upland forests. Silva Fenn 52:articel id 9948. 18 p. https://doi.org/ 10.14214/sf. 9948

Horn R, Vossbrink J, Peth S, Becker S (2007) Impact of modern forest vehicles on soil physical properties. For Ecol Manag 248:56-63. https://doi.org/10.1016/j.foreco.2007.02.037

Karafiath L, Nowatski EA (1978) Soil mechanics for off-road vehicle engineering. Trans Tech Publications, Clausthal

Kozlowski TT (1999) Soil compaction and growth of woody plants. Scand J For Res 14:596-619. https://doi.org/10.1080/ 02827589908540825

Labelle ER, Poltorak BJ, Jaeger D (2019) The role of brush mats in mitigating machine-induced soil disturbances: an assessment using absolute and relative soil bulk density and penetration resistance. Can J For Res 49:164-178. https://doi.org/10.1139/cjfr-2018-0324

Liu K, Ayers P, Howard H, Anderson A (2010) Influence of soil and vehicle parameters on soil rut formation. J Terramech 47:143-150. https://doi.org/10.1016/j.jterra.2009.09.001
Marra E, Cambi M, Fernandez-Lacruz R et al (2018) Photogrammetric estimation of wheel rut dimensions and soil compaction after increasing numbers of forwarder passes. Scand J For Res 33:613620. https://doi.org/10.1080/02827581.2018.1427789

Murphy G, Brownlie R, Kimberley M, Beets P (2009) Impacts of forest harvesting related soil disturbance on end-of-rotation wood quality and quantity in a New Zealand radiata pine forest. Silva Fenn 43:147-160

Périé C, Ouimet R (2011) Organic carbon, organic matter and bulk density relationships in boreal forest soils. Can J Soil Sci 88:315-325. https://doi.org/10.4141/cjss06008

Poltorak BJ, Labelle ER, Jaeger D (2018) Soil displacement during ground-based mechanized forest operations using mixed-wood brush mats. Soil Tillage Res 179:96-104. https://doi.org/10.1016/j. still.2018.02.005

Saarilahti M (2002) Soil interaction model. ECOWOOD project deliverable D2. Helsinki, Finland

Sakai H, Nordfjell T, Suadicani K et al (2008) Soil compaction on forest soils from different kinds of tires and tracks and possibility of accurate estimate. Croat J For Eng 29:15-27

Sirén M, Ala-Ilomäki J, Mäkinen H et al (2013) Harvesting damage caused by thinning of Norway spruce in unfrozen soil. Int $\mathrm{J}$ For Eng 24:60-75. https://doi.org/10.1080/19132220.2013.792155

Sirén M, Ala-ilomäki J, Lindeman H et al (2019a) Soil disturbance by cut-to-length machinery on mid. Silva Fenn 53:1-24. https://doi.org/ 10.14214/sf.10134

Sirén M, Salmivaara A, Ala-Ilomäki J et al (2019b) Predicting forwarder rut formation on fine-grained mineral soils. Scand J For Res 34:145154. https://doi.org/10.1080/02827581.2018.1562567

Smith CW, Johnston M, Lorentz S (1997) The effect of soil compaction and soil physical properties on the mechanical resistance of South African forestry soils. Geoderma 78:93-111. https://doi.org/10. 1016/S0016-7061(97)00029-3

Suomen Metsäkeskus (2019) Maastotarkastusohje. 1-64

Toivio J, Helmisaari H-S, Palviainen M et al (2017) Impacts of timber forwarding on physical properties of forest soils in southern Finland. For Ecol Manag 405. https://doi.org/10.1016/j.foreco.2017.09.022

Turnage GW (1984) Prediction of in-sand tire and wheeled vehicle drawbar performance. In: Proceedings of the 8th International ISTVS Conference, 6 10. July 1984, Cambridge, UK

Uusitalo J, Ala-Ilomäki J (2013) The significance of above-ground biomass, moisture content and mechanical properties of peat layer on the bearing capacity of ditched pine bogs. Silva Fenn 47. https://doi. org/10.14214/sf.993

Uusitalo J, Salomäki M, Ala-Illomäki J (2015) The effect of wider logging trails on rut formations in the harvesting of peatland forests

Uusitalo J, Ala-Ilomäki J, Lindeman H et al (2019) Modelling soil moisture - soil strength relationship of fine-grained upland forest soils. Silva Fenn 53:article id 10050. 16 p. https://doi.org/10.14214/sf.10050

Vega-Nieva DJD, Murphy PNC, Castonguay M et al (2009) A modular terrain model for daily variations in machine-specific forest soil trafficability. Can J Soil Sci 89:93-109. https://doi.org/10.4141/ CJSS06033

Vossbrink J, Horn R (2004) Modern forestry vehicles and their impact on soil physical properties. Eur J For Res 123:259-267. https://doi.org/ 10.1007/s10342-004-0040-8

Westman CJ (1990) Metsämaan fysikaaliset ja fysikaalis-kemialliset ominaisuudet CT-OMaT kasvupaikkasarjassa [soil physical and physico-chemical properties of Finnish upland forest sites]. Silva Fenn 24:41-158. https://doi.org/10.14214/sf.a15568

Publisher's note Springer Nature remains neutral with regard to jurisdictional claims in published maps and institutional affiliations. 